Article

\title{
Living with Overweight, Rather than a History of Gestational Diabetes, Influences Dietary Quality and Physical Activity during Pregnancy
}

\author{
Ella Muhli ${ }^{1}\left(\mathbb{D}\right.$, Ella Koivuniemi ${ }^{1}$ (D) and Kirsi Laitinen ${ }^{1,2, * \mathbb{D}}$
}

check for

updates

Citation: Muhli, E.; Koivuniemi, E.;

Laitinen, K. Living with Overweight, Rather than a History of Gestational Diabetes, Influences Dietary Quality and Physical Activity during Pregnancy. Nutrients 2022, 14, 651. https://doi.org/10.3390/ nu14030651

Academic Editors: Annalisa Terranegra and Cinzia

Myriam Calabrese

Received: 18 January 2022

Accepted: 1 February 2022

Published: 3 February 2022

Publisher's Note: MDPI stays neutral with regard to jurisdictional claims in published maps and institutional affiliations.

Copyright: (C) 2022 by the authors. Licensee MDPI, Basel, Switzerland. This article is an open access article distributed under the terms and conditions of the Creative Commons Attribution (CC BY) license (https:// creativecommons.org/licenses/by/ $4.0 /)$.
1 Research Centre for Integrative Physiology and Pharmacology, Institute of Biomedicine, University of Turku, 20014 Turku, Finland; elromu@utu.fi (E.M.); elmkoi@utu.fi (E.K.)

2 Department of Obstetrics and Gynecology, Turku University Hospital, 20521 Turku, Finland

* Correspondence: kirsi.laitinen@utu.fi

\begin{abstract}
Background: Clinical practice guidelines recommend dietary and physical activity counselling for pregnant women with gestational diabetes (GDM). The aim of this study was to evaluate the extent to which a history of GDM and living with overweight before pregnancy modify dietary quality and physical activity during pregnancy. (2) Methods: The study is a cross-sectional study of 1034 pregnant women from different parts of Finland. The data were collected through electronic questionnaires. Dietary quality and physical activity were measured with stand-alone indices and compared according to the history of GDM and overweight status based on body mass index (BMI) category. (3) Results: Overall, $53 \%$ of the women had a poor dietary quality (Index of Diet Quality (IDQ) score $<10$ ) and $45 \%$ a light physical activity level. The IDQ score or physical activity levels did not differ between women with and without a history of GDM. Instead, in women with overweight/obesity both the IDQ score and physical activity levels were lower compared to their normal-weight counterparts $(p<0.001)$. (4) Conclusions: Pregnant women, particularly if living with overweight, commonly have a poor dietary quality and a light level of physical activity. A history of GDM is not reflected in the lifestyle habits, despite the assumption that they have received lifestyle counselling during a previous pregnancy. Pregnant women would benefit from new means to promote healthy lifestyle changes.
\end{abstract}

Keywords: diet; physical activity; pregnancy; overweight; obesity; gestational diabetes

\section{Introduction}

There is an alarming trend that more and more pregnant women are living with overweight as this condition predisposes both mother and child to health complications, including an increased risk of gestational diabetes (GDM) [1]. GDM refers to diabetes first manifesting during pregnancy [2], currently diagnosed in approximately 15\% of women [3]. In Finland, where this study was conducted, the value may be as high as one in every five [4]. Not only does GDM increase the risks of serious perinatal complications in the offspring [5], but it also may lead to serious health complications like type 2 diabetes after the pregnancy $[6,7]$.

Conventional strategies to promote the pregnant woman's health include counselling on dietary and physical activity habits $[8,9]$ and regular maternity care visits which represent an excellent opportunity to provide that vital information. In Finland, the standard prenatal care for all women includes at least nine visits for primiparas and at least eight visits for multiparas. In line with the current care guidelines [10], women with GDM receive diet and exercise counselling from maternity care nurses in communal health centers. The aims of the counselling are maintaining normoglycemia and preventing excessive gestational weight gain by providing practical advice. In most cases, GDM can be controlled with lifestyle modifications alone [11]. While one might expect that pregnant women with 
a history of GDM will have improved their dietary quality as they have previously received dietary counselling, in fact, up till now the dietary quality and physical activity of pregnant women with a history of GDM have not been evaluated.

A good dietary quality signifies an adherence to a health-promoting diet as defined in dietary recommendations with a high consumption of vegetables, fruits and berries, whole grain foods, vegetable oil-based spread and low-fat dairy, together with a low consumption of sugary beverages and food high in saturated fats. A higher dietary quality has been associated with a lower risk of obesity in both pregnant and non-pregnant adults [12,13]. Because of this we hypothesized that the dietary quality of women with overweight or obesity when they are pregnant would deviate from that recommended. We aimed to evaluate the overall quality of the diet with a stand-alone validated index, specifically designed to reflect dietary recommendations [14].

The first aim of the present study was to determine the dietary quality and physical activity with stand-alone indices $[14,15]$ in a sample from different parts of Finland of pregnant women who had been diagnosed with GDM in a previous pregnancy compared to those without history of GDM. The second aim was to evaluate the dietary quality and physical activity in women with overweight or obesity as compared to women with normal weight during pregnancy.

\section{Materials and Methods}

\subsection{Study Design}

Women were recruited into a study investigating lifestyle and the use of a mobile application during pregnancy by announcements in social media (Facebook) running from June to October 2017. The data at the baseline of the study are reported here in a cross-sectional design. We wanted to recruit a cohort of women in early to mid-pregnancy, so the criteria for inclusion were less than gestational week 28 and Finnish language skills. The women interested in the study $(n=1512)$ contacted the researcher via an electronic form and those who were eligible, were subsequently provided with further information about the study and sent the study questionnaires by e-mail. A total of 1047 women participated in the study. Ten questionnaires were excluded based on missing information on gestational weeks or gestational weeks $\geq 28$ and 3 questionnaires were excluded based on no weight and/or height reported.

Data on dietary quality, physical activity, use of dietary supplements, current health status, height and weight were collected through electronic questionnaires. With respect to diet and physical activity, the data were collected at a mean week of 14.9 (standard deviation (SD) 6.4) during pregnancy. The diagnosis of prior GDM was self-reported. Based on the Finnish guidelines [10], nearly all pregnant women undergo a 2-h oral glucose tolerance test between gestational weeks 24 and 28 . A diagnosis is made if blood glucose is at or above the threshold levels in one or more timepoints: $0 \mathrm{~h} 5.3 \mathrm{mmol} / \mathrm{L}, 1 \mathrm{~h} 10.0 \mathrm{mmol} / \mathrm{L}$, $2 \mathrm{~h} 8.6 \mathrm{mmol} / \mathrm{L}$. When comparing the study cohort to the population of pregnant women in Finland [4], we also collected data on locality, age, parity, marital status, education, household income (low income defined as less than 20,000 euros/year based on an income less than 60 percent of the median household income in Finland [16]), previous health conditions, smoking status, and adherence to special diets.

\subsection{Measures}

Dietary quality was inquired by a validated Index of Diet Quality (IDQ) designed to reflect the Nordic and Finnish nutrition recommendations [14]. The IDQ is comprised of 18 multiple-choice questions about the frequency and quality of consuming foods. The total IDQ score ranges from 0 to 15 points such that scores $\geq 10$ are considered as healthpromoting (good dietary quality), thus a score $<10$ is designated as a poor dietary quality. Some components (vegetables, fruit and berries, whole-grain products, vegetable oil -based spread, fish, and meal pattern) of the IDQ were also individually compared to dietary recommendations as categorized variables (yes/no). 
Leisure-time physical activity (LTPA) was measured using the metabolic equivalent (MET)-index which consists of three multiple-choice questions inquiring about the intensity, frequency, and duration of physical activity in leisure-time [15]. The total score ranges from 0 to $105 \mathrm{MET} \mathrm{h} /$ week (h/wk). The index was further categorized to light LTPA ( $<5 \mathrm{MET} h / w k)$, moderate LTPA ( $\geq 5$ but $\leq 30 \mathrm{MET} \mathrm{h} / \mathrm{wk})$, and vigorous LTPA (>30 MET h/wk). Level $5 \mathrm{MET} \mathrm{h/wk} \mathrm{corresponds} \mathrm{to} \mathrm{about} \mathrm{one} \mathrm{hour} \mathrm{of} \mathrm{moderate-intensity}$ physical activity weekly and level $30 \mathrm{MET} \mathrm{h/wk}$ to about one hour of moderate-intensity physical activity every day [15].

\subsection{Data Analysis}

In the analyses, the participating women were assigned to either a group with normal weight (body mass index (BMI) $<25.0 \mathrm{~kg} / \mathrm{m}^{2}$ ) or a group with overweight/obesity $\left(\mathrm{BMI} \geq 25.0 \mathrm{~kg} / \mathrm{m}^{2}\right)$ based on their pre-pregnancy BMI. The women with underweight $(n=22)$ were included in the normal-weight group since they did not differ significantly in terms of either their IDQ score or MET-index. Primiparous women were excluded from the analyses when the women with a history of GDM were compared to the women who had not been diagnosed with this condition in their previous pregnancy.

No imputations regarding missing data were conducted. The normality of the data was observed from histograms and homogeneity of variances checked with Levene's test. Categorical data are presented as frequencies and percentages and normally distributed continuous variables as means and standard deviations. As MET-indices were not normally distributed, these data are summarized as medians and interquartile ranges.

Comparisons for categorical data were made with Fisher's exact test or the Chi-square test. MET-indices were compared using the Mann-Whitney U-test or the Kruskal-Wallis test. Independent samples T-test or one-way ANOVA was used to compare age, gestational weeks, pre-pregnancy BMI and IDQ scores between groups. When the women were divided into subgroups based on a history of GDM and pre-pregnancy BMI, a post hoc Tukey test was used to compare the IDQ scores.

Possible confounding factors were considered, and models of the IDQ score adjusted for age and/or pre-pregnancy BMI were made with ANCOVA. Pre-pregnancy BMI, university education and pre-pregnancy smoking status intercorrelated strongly and therefore the model was adjusted with pre-pregnancy BMI only.

Two-sided $p$-values $<0.05$ were considered significant. Analyses were executed with IBM SPSS statistics version 25.0 for Windows (IBM SPSS Inc., Chicago, IL, USA).

\section{Results}

\subsection{Clinical Characteristics}

The study population consisted of 1034 pregnant women from different parts of Finland (Supplementary Table S1). As indicated in Table 1, 37\% of the women were living with overweight $(23 \%)$ or obesity $(14 \%)$. Of the multipara women, $18 \%$ reported having been diagnosed with GDM in a previous pregnancy, which is in accordance with the value in the general population (19\%) [4].

The women with and without a history of GDM did not differ significantly with respect to mean age, parity, marital status, university education, or income (Table 1). However, the women with a history of GDM had a higher pre-pregnancy BMI, and they had smoked more commonly before pregnancy. No significant differences were evident between the characteristics of the women with normal weight and the women with overweight/obesity, except that the women with overweight/obesity had less frequently a university-level education and had smoked more commonly before pregnancy.

\subsection{Dietary Quality and Physical Activity According to the History of GDM Status}

Overall, $53 \%$ of the women had a poor dietary quality, but as shown in Table 2, the IDQ scores did not differ between the women with and without a history of GDM (mean 9.2 (SD 2.2) and mean 9.4 (SD 2.2), respectively), not even after adjusting for pre-pregnancy BMI. 
Furthermore, there were no significant differences in the individual components of the IDQ score between the groups (Table 3). When compared with the women with a history of GDM, those without were more likely to consume whole-grain products on a daily basis $(p=0.062)$. There were no significant differences in the frequency of using dietary supplements between the women with and without a history of GDM (Supplementary Table S2).

Table 1. Clinical characteristics of the women subdivided by history of gestational diabetes or their pre-pregnancy BMI values.

\begin{tabular}{|c|c|c|c|c|c|c|c|}
\hline & $\begin{array}{c}\text { All } \\
\text { Women }\end{array}$ & $\begin{array}{l}\text { Women with } \\
\text { No History } \\
\text { of GDM }\end{array}$ & $\begin{array}{c}\text { Women with } \\
\text { a History of } \\
\text { GDM }\end{array}$ & $\begin{array}{c}\text { Women with } \\
\text { Normal } \\
\text { Weight }\end{array}$ & $\begin{array}{l}\text { Women with } \\
\text { Over- } \\
\text { Weight/Obesity }\end{array}$ & & \\
\hline & $n=1034$ & $n=383$ & $n=86$ & $n=656$ & $n=378$ & $p$-Value ${ }^{a}$ & $p$-Value ${ }^{b}$ \\
\hline $\begin{array}{l}\text { Age (years), mean } \\
\text { (SD) }\end{array}$ & $29.4(4.0)$ & $30.3(3.8)$ & $30.8(4.3)$ & $29.2(3.8)$ & $29.7(4.2)$ & $0.35^{\mathrm{c}}$ & $0.077^{\mathrm{c}}$ \\
\hline $\begin{array}{l}\text { Pre-pregnancy BMI } \\
\left(\mathrm{kg} / \mathrm{m}^{2}\right) \text {, mean }(\mathrm{SD})\end{array}$ & $24.8(4.9)$ & $24.5(4.5)$ & $28.0(6.5)$ & $21.9(1.8)$ & $29.9(4.4)$ & $<0.001^{\mathrm{c}}$ & $<0.001^{\mathrm{c}}$ \\
\hline Parity, $n(\%)$ & & & & & & $0.97^{\mathrm{d}}$ & $0.15^{\mathrm{d}}$ \\
\hline 0 & $560(54)$ & $0(0)$ & $0(0)$ & $371(57)$ & $189(50)$ & & \\
\hline 1 & $315(31)$ & $257(67)$ & $58(67)$ & $190(29)$ & $125(33)$ & & \\
\hline 2 & $102(10)$ & $84(22)$ & $18(21)$ & $65(10)$ & $37(10)$ & & \\
\hline$\geq 3$ & $52(5)$ & $42(11)$ & $10(12)$ & $28(4)$ & $24(6)$ & & \\
\hline Marital status, $n(\%)$ & & & & & & $0.73^{\mathrm{e}}$ & $0.92^{d}$ \\
\hline Married & $518(50)$ & $230(60)$ & $52(61)$ & $331(51)$ & $187(50)$ & & \\
\hline Cohabiting & $474(46)$ & $143(37)$ & $31(36)$ & $301(46)$ & $173(46)$ & & \\
\hline Single & $27(3)$ & $4(1)$ & $2(2)$ & $16(2)$ & $11(3)$ & & \\
\hline Other & $14(1)$ & $6(12)$ & $1(1)$ & $8(1)$ & $6(2)$ & & \\
\hline $\begin{array}{c}\text { University degree, } n \\
(\%)\end{array}$ & $690(67)$ & $229(60)$ & $56(65)$ & $456(70)$ & $234(62)$ & $0.39^{\mathrm{e}}$ & $0.014^{\mathrm{e}}$ \\
\hline Low income, $n(\%)$ & $82(8)$ & $28(7)$ & $8(9)$ & $49(8)$ & $33(9)$ & $0.50^{\mathrm{e}}$ & $0.55^{\mathrm{e}}$ \\
\hline \multicolumn{8}{|l|}{ Smoking status, $n(\%)$} \\
\hline $\begin{array}{l}\text { Smoked before } \\
\text { pregnancy }\end{array}$ & $169(16)$ & $50(13)$ & $20(23)$ & $84(13)$ & $85(23)$ & $0.028^{\mathrm{e}}$ & $<0.001^{\mathrm{e}}$ \\
\hline $\begin{array}{l}\text { Smoked during } \\
\text { pregnancy }\end{array}$ & $23(2)$ & $9(2)$ & $3(4)$ & $13(2)$ & $10(3)$ & $0.46^{\mathrm{e}}$ & $0.52^{\mathrm{e}}$ \\
\hline $\begin{array}{c}\text { Chronic disease }{ }^{\mathrm{f}}, n \\
(\%)\end{array}$ & $120(12)$ & $43(11)$ & $14(16)$ & $70(11)$ & $50(13)$ & $0.20^{\mathrm{e}}$ & $0.23^{\mathrm{e}}$ \\
\hline Special diet $\mathrm{g}, n(\%)$ & $276(27)$ & $97(25)$ & $26(30)$ & $182(28)$ & $94(25)$ & $0.35^{\mathrm{e}}$ & $0.34^{\mathrm{e}}$ \\
\hline
\end{tabular}

GDM, gestational diabetes; SD, standard deviation; BMI, body mass index; ${ }^{\text {a between history of GDM groups }}$ ${ }^{b}$ between normal-weight group and group with overweight/obesity; ${ }^{\mathrm{C}}$ Independent samples T-test; ${ }^{\mathrm{d}}$ Chi-square test; ${ }^{\mathrm{e}}$ Fisher's exact test; ${ }^{\mathrm{f}}$ Type 1 diabetes $(0.3 \%)$, type 2 diabetes $(0.1 \%)$, cardiovascular disease $(1.6 \%)$, coeliac disease $(1.9 \%)$, irritable bowel syndrome $(6.9 \%)$, or inflammatory bowel disease $(1.3 \%)$; ${ }^{\mathrm{g}}$ Lactose-free $(4.8 \%)$, milk-free $(0.7 \%)$, gluten-free $(3.1 \%)$, vegetarian $(4.4 \%)$, low fermentable oligo-, di-, monosaccharides and polyols (low FODMAP, $1.2 \%)$, or several of these $(12 \%)$ diets.

Table 2. Dietary quality and physical activity in the women without and those with a history of gestational diabetes.

\begin{tabular}{|c|c|c|c|c|c|}
\hline & All Women & $\begin{array}{l}\text { Women with No } \\
\text { History of GDM }\end{array}$ & $\begin{array}{l}\text { Women with a } \\
\text { History of GDM }\end{array}$ & & \\
\hline & $n=1034$ & $n=383$ & $n=86$ & $p$-Value ${ }^{a}$ & $p$-Value ${ }^{\mathrm{b}}$ \\
\hline $\begin{array}{l}\text { IDQ score, mean (SD), } \\
\text { adjusted mean }(95 \% \text { CI) }\end{array}$ & $9.3(2.2)$ & $9.3(9.1,9.5)$ & $9.5(9.0,9.9)$ & $0.68^{c}$ & $0.61^{\mathrm{d}}$ \\
\hline Good dietary quality, $n(\%)$ & $479(47)$ & $173(45)$ & $38(46)$ & $1.0^{\mathrm{e}}$ & \\
\hline $\begin{array}{l}\text { MET-index (MET h/wk), } \\
\text { median (IQR) }\end{array}$ & $7.5(12.0)$ & $4.8(10.1)$ & $4.8(10.1)$ & $0.58^{\mathrm{f}}$ & \\
\hline Categorized MET-index, $n(\%)$ & & & & $0.75^{\mathrm{g}}$ & \\
\hline
\end{tabular}


Table 2. Cont.

\begin{tabular}{|c|c|c|c|c|c|}
\hline & All Women & $\begin{array}{l}\text { Women with No } \\
\text { History of GDM }\end{array}$ & $\begin{array}{l}\text { Women with a } \\
\text { History of GDM }\end{array}$ & & \\
\hline & $n=1034$ & $n=383$ & $n=86$ & $p$-Value ${ }^{a}$ & $p$-Value ${ }^{b}$ \\
\hline Light LTPA & $460(45)$ & $198(52)$ & $44(52)$ & & \\
\hline Moderate LTPA & $450(44)$ & $146(38)$ & $35(41)$ & & \\
\hline Vigorous LTPA & $117(11)$ & $36(10)$ & $6(7)$ & & \\
\hline
\end{tabular}

IDQ, Index of Diet Quality; CI, confidence interval; MET, metabolic equivalent; IQR, interquartile range; LTPA, leisure-time physical activity. ${ }^{a}$ between history of GDM groups, unadjusted; ${ }^{b}$ between history of GDM groups, adjusted for pre-pregnancy BMI; ${ }^{\mathrm{c}}$ Independent samples T-test; ${ }^{\mathrm{d}}$ ANCOVA, adjusted for pre-pregnancy BMI; e Fisher's exact test; ${ }^{\mathrm{f}}$ Mann-Whitney U-test; ${ }^{\mathrm{g}}$ Chi-square test.

Table 3. Adherence to dietary recommendations in all the women, in the women without and those with a history of gestational diabetes and in the women with normal weight and women with overweight/obesity.

\begin{tabular}{|c|c|c|c|c|c|c|c|}
\hline & All Women & $\begin{array}{l}\text { Women with } \\
\text { No History } \\
\text { of GDM }\end{array}$ & $\begin{array}{l}\text { Women with } \\
\text { a History of } \\
\text { GDM }\end{array}$ & $\begin{array}{c}\text { Women with } \\
\text { Normal } \\
\text { Weight }\end{array}$ & $\begin{array}{l}\text { Women with } \\
\text { Over- } \\
\text { Weight/Obesity }\end{array}$ & & \\
\hline & $\begin{array}{c}n=1034 \\
n(\%)\end{array}$ & $\begin{array}{c}n=383 \\
n(\%)\end{array}$ & $\begin{array}{c}n=86 \\
n(\%)\end{array}$ & $\begin{array}{c}n=656 \\
n(\%)\end{array}$ & $\begin{array}{c}n=378 \\
n(\%)\end{array}$ & $p$-Value ${ }^{a}$ & $p$-Value ${ }^{\mathrm{b}}$ \\
\hline Vegetables daily & 709 (69) & $262(69)$ & $63(76)$ & $466(72)$ & $243(65)$ & $0.23^{c}$ & $0.017^{c}$ \\
\hline Fruit or berries daily & $554(54)$ & $197(52)$ & $46(55)$ & $383(59)$ & $171(46)$ & $0.55^{\mathrm{c}}$ & $<0.001^{\mathrm{c}}$ \\
\hline $\begin{array}{l}\text { Vegetables, fruit or } \\
\text { berries } \geq 5 \text { portions } \\
\text { daily }\end{array}$ & $436(43)$ & $157(41)$ & $37(45)$ & $292(45)$ & $144(38)$ & $0.62^{\mathrm{c}}$ & $0.042^{\mathrm{c}}$ \\
\hline $\begin{array}{l}\text { Whole-grain } \\
\text { products daily }\end{array}$ & $610(60)$ & $243(64)$ & $44(53)$ & $425(66)$ & $185(49)$ & $0.062^{c}$ & $<0.001^{\mathrm{c}}$ \\
\hline $\begin{array}{l}\text { Vegetable oil -based } \\
\text { spread on bread }\end{array}$ & $331(32)$ & $129(34)$ & $27(33)$ & $212(33)$ & $119(32)$ & $0.90^{\mathrm{c}}$ & $0.78^{\mathrm{c}}$ \\
\hline $\begin{array}{c}\text { Fish } \geq 2 \text { portions } \\
\text { weekly }\end{array}$ & $291(28)$ & $107(28)$ & $18(22)$ & $196(30)$ & $95(25)$ & $0.28^{c}$ & $0.098^{c}$ \\
\hline Regular meal pattern & $918(90)$ & $335(88)$ & $77(93)$ & $602(93)$ & $316(84)$ & $0.25^{c}$ & $<0.001^{\mathrm{c}}$ \\
\hline
\end{tabular}

${ }^{a}$ between history of GDM groups; ${ }^{b}$ between normal-weight group and group with overweight/obesity; ${ }^{c}$ Fisher's exact test.

Most of the women were undertaking either light or moderate physical activity; $52 \%$ of those with a history of GDM were undertaking light physical activity (Table 2), but the physical activity levels or the MET-index did not differ between the groups.

\subsection{Dietary Quality and Physical Activity According to the Overweight Status}

Having a good dietary quality was significantly more common in the women with normal weight than in their counterparts with overweight/obesity (Table 4). The IDQ score of the women with normal weight (mean 9.6 (SD 2.0)) was also higher than that of the women with overweight/obesity (mean 8.9 (SD 2.3)). When evaluating the individual components of the IDQ score, women with overweight/obesity were less likely to be eating vegetables, fruit or berries, and whole-grain products on a daily basis (Table 3). In addition, they were less likely to consume at least five portions of vegetables, fruit or berries daily and more likely to have an irregular meal pattern. In the evaluation of the frequency of using food supplements, the women with overweight/obesity more likely used multivitamin supplements regularly than the women with normal weight but were less likely to consume any probiotics (Supplementary Table S2).

The women with overweight/obesity had more commonly a light physical activity level than the women with normal weight (Table 4). In addition, the women with overweight/obesity had a significantly lower median MET-index. 
When we divided the women into subgroups based on both living with overweight/ obesity and a history of GDM, the normal-weight women without a history of GDM had a significantly higher IDQ score than the women with overweight/obesity who had not experienced GDM in their past pregnancy (Supplementary Table S3, post hoc Tukey test, $p<0.001)$. The normal-weight groups had more commonly a good dietary quality than the groups with overweight/obesity, regardless of their GDM status. No significant differences were evident in physical activity.

Table 4. Dietary quality and physical activity in the women with normal weight and in the women with overweight/obesity.

\begin{tabular}{|c|c|c|c|c|}
\hline & $\begin{array}{c}\text { Women with Normal } \\
\text { Weight }\end{array}$ & $\begin{array}{l}\text { Women with } \\
\text { OverWeight/Obesity }\end{array}$ & & \\
\hline & $n=656$ & $n=378$ & $p$-Value ${ }^{\mathrm{a}}$ & $p$-Value ${ }^{b}$ \\
\hline IDQ score, adjusted mean (95\% CI) & $9.6(9.5,9.8)$ & $8.8(8.6,9.1)$ & $<0.001^{\mathrm{c}}$ & $<0.001^{\mathrm{d}}$ \\
\hline Good dietary quality, $n(\%)$ & $341(53)$ & $138(37)$ & $<0.001^{\mathrm{e}}$ & \\
\hline MET-index (MET h/wk), median (IQR) & $7.5(15.8)$ & $4.8(10.8)$ & $<0.001^{\mathrm{f}}$ & \\
\hline Categorized MET-index, $n(\%)$ & & & $<0.001 \mathrm{~g}$ & \\
\hline Light LTPA & $255(39)$ & $205(54)$ & & \\
\hline Moderate LTPA & $309(48)$ & $141(37)$ & & \\
\hline Vigorous LTPA & $86(13)$ & $31(8)$ & & \\
\hline
\end{tabular}

a unadjusted; ${ }^{\mathrm{b}}$ adjusted for age; ${ }^{\mathrm{c}}$ Independent samples T-test; ${ }^{\mathrm{d}}$ ANCOVA, adjusted for age; ${ }^{\mathrm{e}}$ Fisher's exact test; ${ }^{f}$ Mann-Whitney U-test; $g$ Chi-square test.

\section{Discussion}

We demonstrated that approximately only half of the Finnish pregnant women studied here had a good overall dietary quality, and furthermore, in early to mid-pregnancy, a light level of physical activity was evident in almost one out of every two. Based on our results, the group of women most at risk for experiencing a pregnancy-related complication, i.e., the women with a history of GDM, did not differ from those without a history of GDM in terms of dietary quality or physical activity. It was also more common that the women with overweight/obesity consumed a poor-quality diet, as evaluated by the IDQ, and had a lower physical activity level during pregnancy than the women with normal weight.

A novel finding in our study was that a low dietary quality score and a light physical activity level were commonly encountered during pregnancy in the women with a history of GDM. This is worrying as these individuals carry a high risk for recurrent GDM [17]. In a previous study examining dietary quality within 10 years following a pregnancy affected with GDM, it was noted that the women with a history of GDM had a lower dietary quality score than those with no such history [18]. Women with a history of GDM have also been reported still to have a lower intensity of physical activity four years after pregnancy [19]. These findings, when combined with our new data, highlight the importance of focusing interventions on this risk population of pregnant women. The possible reasons for the unhealthy dietary and exercise habits in pregnant women with a history of GDM could be either a lack of knowledge or poor motivation. It is also possible that there is a lack of awareness among health care professionals of this group of mothers, who would need targeted dietary and exercise counselling as counselling practices in the communal health centers in Finland are known to be somewhat variable [20]. It is recommended that the dietary counselling for women with GDM should be tailored to the individual, practical, and given repeatedly [10], but it is possible that these are not sufficiently implemented due to limited resources. Increasing healthy eating and physical activity may manifest as clinically improved health as demonstrated in a trial where the risk of GDM was reduced by combined dietary and physical activity counselling given above the standard antenatal care [21]. Further training of the maternity care personnel and allocating resources to dietary and physical activity counselling in maternity care could be beneficial. However, changing the diet and physical activity habits in an effective way is challenging and new 
means alongside counselling might be needed to prevent the development of GDM [3] Exploitation of digital approaches alongside standard care could prove to be feasible as these have shown promising results in the management of GDM [22].

We detected a lower dietary quality score in women with overweight/obesity compared to women with normal weight or underweight during pregnancy. This finding is in accordance with two previous American reports [13,23] and the Norwegian Mother and Child Cohort Study [24], which however used a different approach for the evaluation of the dietary quality score, i.e., calculation based on food frequency questionnaires, whilst our index was based on a specifically developed and validated stand-alone questionnaire to assess the overall diet with respect to that recommended [14]. In a recent study of women living with obesity, intakes of both macro- and micronutrients during pregnancy were found to be suboptimal [25]. As expected, the women with overweight/obesity in our study had a lower physical activity level and a lower level of education than the women with normal weight and they were more likely to have been smokers before they became pregnant, which suggests that not only a low dietary quality, but many other adverse lifestyle factors coalesce in women living with overweight or obesity, calling for new means to improve lifestyle habits in this at-risk group of women. This is of importance also due to the health risks that extend beyond pregnancy, including a heightened risk of type 2 diabetes in women with GDM [6]. Indeed, improving the dietary quality during pregnancy has been shown to be associated with a lowered weight gain up to eight years postpartum [26]. Based on our subgroup analysis, a normal or underweight pre-pregnancy BMI seemed to be a stronger indicator of good dietary habits than a history of GDM. This could be partly explained by the higher educational status of the normal-weight women in comparison to the women with overweight/obesity. Studies with a larger number of participants with prior GDM are required to clarify this observation.

In our study, only about every second woman met the recommended $150 \mathrm{~min}$ of physical activity weekly during pregnancy [27]; this value represented the category of moderate LTPA. This was slightly more than in the previous studies where the fulfilment of the recommendation was observed in less than every third woman in the first trimester of pregnancy [28] and in every fifth woman between weeks 10 and 24 of gestation [29]. Similar to our results, higher physical activity levels during pregnancy have been detected in women with normal weight as compared to women with overweight/obesity [28]. Regular exercise is known to improve blood glucose control [30] and could therefore be an important focus point for intervention strategies. In women with obesity, a higher level of physical activity has been shown to associate with better glycemic control five years postpartum [31].

The study population characteristics (Table 1) were close to the values reported in the Finnish perinatal statistics [4], e.g., the mean age of parturients (30.9 years in the perinatal statistics), the mean pre-pregnancy BMI $\left(24.8 \mathrm{~kg} / \mathrm{m}^{2}\right)$, marital status ( $54 \%$ married), and the home region of the participants (Supplementary Table S1). These data indicated that the study population was representative of pregnant women throughout Finland, except that primiparous women were somewhat over-represented ( $41 \%$ in the perinatal statistics) and there was an under-representation of women who smoked during pregnancy $(13 \%$ in the perinatal statistics) in the study. In addition, compared to Finnish women aged 15 or over [32], the study population had more likely a university degree ( $48 \%$ in the official education statistics).

The strength of this study was that it examined a representative sample of pregnant women from different parts of Finland, with the exception of the higher level of education of the participants, a typical characteristic of survey studies. Other strengths were its large sample size and its use of a validated stand-alone index to measure dietary quality. We also examined possible confounding factors. We recruited participants through social media, which is a recruitment method that fits modern lifestyles, especially pregnant women in the younger age groups [33] while this approach has also been shown to be an effective recruitment strategy in observational studies [34]. Self-reporting of the data may 
have introduced some inaccuracies. In addition, we did not inquire or exclude multiple pregnancies which might slightly influence the results, although the proportion of multiple pregnancies is only $1 \%$ in the general population [4], and thus also likely to have been similar in our participants. The IDQ was originally validated in non-pregnant adults [14] and the LTPA questionnaire uses terms like "becoming breathless", which might be difficult to use as a marker in the classification of the intensity of physical activity in a pregnant woman. We did not have information on the dietary and physical activity habits of the women with a history of GDM during their previous pregnancies so we could not evaluate whether these had improved or deteriorated in any way. Future prospective studies should focus on evaluating this topic.

\section{Conclusions}

Many pregnant women have a low dietary quality and a light physical activity level in early to mid-pregnancy, this being especially pronounced in women with overweight or obesity. Having a history of GDM is not reflected as a good dietary quality or high physical activity level during pregnancy. New effective intervention strategies should be targeted at pregnant women, particularly women with overweight or obesity and women at risk for recurrent GDM, as these are likely to benefit from more intensive dietary and physical activity counselling from maternity care nurses or any new means to promote healthy lifestyle changes.

Supplementary Materials: The following supporting information can be downloaded at: https: / / www.mdpi.com/article/10.3390/nu14030651/s1, Supplementary Table S1: Home region of the study participants and percentage of births in the area in 2017; Supplementary Table S2: The frequency of using dietary supplements in all the women, in the women with and without a history of gestational diabetes, in the women with normal weight, and the women with overweight/obesity; Supplementary Table S3: Dietary quality and physical activity in the women subdivided by pre-pregnancy BMI and history of gestational diabetes, primiparous women excluded.

Author Contributions: Conceptualization, K.L. and E.K.; Methodology, E.K.; Formal Analysis, E.M.; Investigation, E.K.; Data Curation, K.L.; Writing—Original Draft Preparation, E.M.; Writing—Review and Editing, K.L.; Supervision, K.L.; Project Administration, K.L. and E.K.; Funding Acquisition, K.L. All authors have read and agreed to the published version of the manuscript.

Funding: This research was funded by Business Finland (grant number 3486/31/2015).

Institutional Review Board Statement: The study was conducted according to the guidelines of the Declaration of Helsinki and approved by the Ethics Committee of the University of Turku (Statement 62/2016) on 12 December 2016.

Informed Consent Statement: Informed consent was obtained from all subjects involved in the study.

Data Availability Statement: The data presented in this study are available upon reasonable request from the corresponding author. The data are not publicly available due to the fact that they contain information that could compromise the privacy of the research participants.

Acknowledgments: Study participants.

Conflicts of Interest: The authors declare no conflict of interest. The sponsors had no role in the design, execution, interpretation, or writing of the study.

\section{References}

1. Shin, D.; Song, W.O. Prepregnancy body mass index is an independent risk factor for gestational hypertension, gestational diabetes, preterm labor, and small- and large-for-gestational-age infants. J. Matern. Fetal Neonatal Med. 2015, 28, 1679-1686. [CrossRef] [PubMed]

2. American Diabetes Association. 2. Classification and Diagnosis of Diabetes: Standards of Medical Care in Diabetes-2018. Diabetes Care 2018, 41 (Suppl. S1), S13-S27. [CrossRef] [PubMed]

3. Griffith, R.J.; Alsweiler, J.; Moore, A.E.; Brown, S.; Middleton, P.; Shepherd, E.; Crowther, C.A. Interventions to prevent women from developing gestational diabetes mellitus: An overview of Cochrane reviews. Cochrane Database Syst. Rev. 2020, 6, CD012394. [PubMed] 
4. National Institute for Health and Welfare. Perinatal Statistics-Parturients, Deliveries and Newborns 2017; Report no. 38/2018; National Institute for Health and Welfare: Helsinki, Finland, 2017.

5. Hilden, K.; Hanson, U.; Persson, M.; Magnuson, A.; Simmons, D.; Fadl, H. Gestational diabetes and adiposity are independent risk factors for perinatal outcomes: A population based cohort study in Sweden. Diabet. Med. 2019, 36, 151-157. [CrossRef]

6. Bellamy, L.; Casas, J.P.; Hingorani, A.D.; Williams, D. Type 2 diabetes mellitus after gestational diabetes: A systematic review and meta-analysis. Lancet 2009, 373, 1773-1779. [CrossRef]

7. Tobias, D.K.; Stuart, J.J.; Li, S.; Chavarro, J.; Rimm, E.B.; Rich-Edwards, J.; Hu, F.B.; Manson, J.E.; Zhang, C. Association of history of gestational diabetes with long-term cardiovascular disease risk in a large prospective cohort of US women. JAMA Intern. Med. 2017, 177, 1735-1742. [CrossRef]

8. Lamminpää, R.; Vehviläinen-Julkunen, K.; Schwab, U. A systematic review of dietary interventions for gestational weight gain and gestational diabetes in overweight and obese pregnant women. Eur. J. Nutr. 2018, 57, 1721-1736. [CrossRef]

9. Muktabhant, B.; Lawrie, T.A.; Lumbiganon, P.; Laopaiboon, M. Diet or exercise, or both, for preventing excessive weight gain in pregnancy. Cochrane Database Syst. Rev. 2015, 6, CD007145. [CrossRef]

10. Working Group Set Up by the Finnish Medical Society Duodecim, the Medical Advisory Board of the Finnish Diabetes Association and the Finnish Gynecological Association. Gestational Diabetes. Current Care Guideline. The Finnish Medical Society Duodecim: Helsinki, Finland, 2013. Available online: www.kaypahoito.fi (accessed on 17 January 2022).

11. American Diabetes Association. 13. Management of Diabetes in Pregnancy. Diabetes Care 2017, 40 (Suppl. S1), S114-S119. [CrossRef]

12. Livingstone, K.M.; McNaughton, S.A. Diet quality is associated with obesity and hypertension in Australian adults: A cross sectional study. BMC Public Health 2016, 16, 1037. [CrossRef]

13. Shin, D.; Lee, K.W.; Song, W.O. Pre-pregnancy weight status is associated with diet quality and nutritional biomarkers during pregnancy. Nutrients 2016, 8, 162. [CrossRef] [PubMed]

14. Leppälä, J.; Lagström, H.; Kaljonen, A.; Laitinen, K. Construction and evaluation of a self-contained index for assessment of diet quality. Scand. J. Public Health 2010, 38, 794-802. [CrossRef] [PubMed]

15. Pahkala, K.; Heinonen, O.J.; Simell, O.; Viikari, J.S.; Rönnemaa, T.; Niinikoski, H.; Raitakari, O.T. Association of physical activity with vascular endothelial function and intima-media thickness. Circulation 2011, 124, 1956-1963. [CrossRef] [PubMed]

16. Official Statistics of Finland (OSF). Income Distribution Statistics. 2017. Available online: https://www.stat.fi/til/tit/2017/index_ en.html (accessed on 13 November 2019).

17. Hod, M.; Kapur, A.; Sacks, D.A.; Hadar, E.; Agarwal, M.; Di Renzo, G.C.; Roura, L.C.; McIntyre, H.D.; Morris, J.L.; Divakar, H. The International Federation of Gynecology and Obstetrics (FIGO) Initiative on gestational diabetes mellitus: A pragmatic guide for diagnosis, management, and care. Int. J. Gynaecol. Obstet. 2015, 131 (Suppl. S3), S173-S211. [CrossRef]

18. Xiao, R.S.; Simas, T.A.; Person, S.D.; Goldberg, R.J.; Waring, M.E. Diet quality and history of gestational diabetes mellitus among childbearing women, United States, 2007-2010. Prev. Chronic Dis. 2015, 12, E25. [CrossRef]

19. Persson, M.; Winkvist, A.; Mogren, I. Lifestyle and health status in a sample of Swedish women four years after pregnancy: A comparison of women with a history of normal pregnancy and women with a history of gestational diabetes mellitus. BMC Pregnancy Childbirth 2015, 15, 57. [CrossRef]

20. Huurre, A.; Laitinen, K.; Hoppu, U.; Isolauri, E. How practice meets guidelines: Evaluation of nutrition counselling in Finnish well-women and well-baby clinics. Acta Paediatr. 2006, 95, 1353-1359. [CrossRef]

21. Koivusalo, S.B.; Rönö, K.; Klemetti, M.M.; Roine, R.P.; Lindström, J.; Erkkola, M.; Kaaja, R.J.; Pöyhönen-Alho, M.; Tiitinen, A.; Huvinen, E.; et al. Gestational diabetes mellitus can be prevented by lifestyle intervention: The Finnish gestational diabetes prevention study (RADIEL): A randomized controlled trial. Diabetes Care 2016, 39, 24-30. [CrossRef]

22. Weihua, X.; Pinyuan, D.; Yu, Q.; Ming, W.; Bingquan, Y.; Xiaojin, Y. Effectiveness of telemedicine for pregnant women with gestational diabetes mellitus: An updated meta-analysis of 32 randomized controlled trials with trial sequential analysis BMC Pregnancy Childbirth 2020, 20, 198.

23. Laraia, B.A.; Bodnar, L.M.; Siega-Riz, A.M. Pregravid body mass index is negatively associated with diet quality during pregnancy. Public Health Nutr. 2007, 10, 920-926. [CrossRef]

24. Hillesund, E.R.; Bere, E.; Haugen, M.; Øverby, N.C. Development of a New Nordic Diet score and its association with gestational weight gain and fetal growth-A study performed in the Norwegian Mother and Child Cohort Study (MoBa). Public Health Nutr. 2014, 17, 1909-1918. [CrossRef] [PubMed]

25. Charnley, M.; Newson, L.; Weeks, A.; Abayomi, J. Pregnant Women Living with Obesity: A Cross-Sectional Observational Study of Dietary Quality and Pregnancy Outcomes. Nutrients 2021, 13, 1652. [CrossRef] [PubMed]

26. Skreden, M.; Hillesund, E.R.; Wills, A.K.; Brantsæter, A.L.; Bere, E.; Øverby, N.C. Adherence to the New Nordic Diet during pregnancy and subsequent maternal weight development: A study conducted in the Norwegian Mother and Child Cohort Study (MoBa). Br. J. Nutr. 2018, 119, 1286-1294. [CrossRef] [PubMed]

27. American College of Obstetricians and Gynecologists. ACOG Committee Opinion No. 650: Physical activity and exercise during pregnancy and the postpartum period. Obstet. Gynecol. 2015, 126, e135-e142.

28. Bacchi, E.; Bonin, C.; Zanolin, M.E.; Zambotti, F.; Livornese, D.; Donà, S.; Tosi, F.; Baldisser, G.; Ihnatava, T.; Di Sarra, D.; et al Physical activity patterns in normal-weight and overweight/obese pregnant women. PLoS ONE 2016, 11, e0166254. [CrossRef] [PubMed] 
29. Walsh, J.M.; McGowan, C.; Byrne, J.; McAuliffe, F.M. Prevalence of physical activity among healthy pregnant women in Ireland. Int. J. Gynaecol. Obstet. 2011, 114, 154-155. [CrossRef]

30. Cremona, A.; O'Gorman, C.; Cotter, A.; Saunders, J.; Donnelly, A. Effect of exercise modality on markers of insulin sensitivity and blood glucose control in pregnancies complicated with gestational diabetes mellitus: A systematic review. Obes. Sci. Pract. 2018, 4, 455-467. [CrossRef]

31. Huvinen, E.; Engberg, E.; Meinilä, J.; Tammelin, T.; Kulmala, J.; Heinonen, K.; Bergman, P.; Stach-Lempinen, B.; Koivusalo, S. Lifestyle and glycemic health 5 years postpartum in obese and non-obese high diabetes risk women. Acta Diabetol. 2020, 57, 1453-1462. [CrossRef]

32. Official Statistics of Finland (OSF). Educational Structure of Population. 2017. Available online: http://www.stat.fi/til/vkour/20 17/vkour_2017_2018-11-02_tie_001_en.html (accessed on 17 January 2022).

33. Whitaker, C.; Stevelink, S.; Fear, N. The use of Facebook in recruiting participants for health research purposes: A systematic review. J. Med. Internet Res. 2017, 19, e290. [CrossRef]

34. Topolovec-Vranic, J.; Natarajan, K. The use of social media in recruitment for medical research studies: A scoping review. J. Med. Internet Res. 2016, 18, e286. [CrossRef] 